\title{
Two-phase survey of eating disorders in gifted dance and non-dance high-school students in Taiwan
}

\author{
MEG MEI-CHIH TSENG ${ }^{1,2,3}$, DAVID FANG ${ }^{4}$, MING-BEEN LEE ${ }^{1}$, WEI-CHU CHIE 2 , \\ JEN-PEI LIU ${ }^{5}$ AND WEI J. CHEN ${ }^{1,2,6 *}$ \\ ${ }^{1}$ Department of Psychiatry, National Taiwan University Hospital and College of Medicine, National \\ Taiwan University, Taipei, Taiwan; ${ }^{2}$ Institute of Preventive Medicine, College of Public Health, National \\ Taiwan University, Taipei, Taiwan; ${ }^{3}$ Institute of Occupational Medicine and Industrial Hygiene, College \\ of Public Health, National Taiwan University, Taipei, Taiwan $;{ }^{4}$ Center for Teacher Education, \\ National Taipei College of Nursing, Taipei, Taiwan; ${ }^{5}$ Division of Biometry, Department of Agronomy, \\ National Taiwan University, Taipei, Taiwan; ${ }^{6}$ Institute of Epidemiology, College of Public Health, \\ National Taiwan University, Taipei, Taiwan
}

\begin{abstract}
Background. Despite a growing body of literature reporting eating disorders (EDs) in non-Western countries in recent years, most of these studies are limited to questionnaire-based surveys or caseseries studies. This study aimed to investigate the prevalence and correlates of EDs in Taiwanese high-school students.
\end{abstract}

Methods. The study subjects consisted of all the female high-school students enrolled in the gifted dance class in 2003 in Taiwan $(n=655)$ and non-dance female students randomly chosen from the same school $(n=1251)$. All the participants were asked to complete self-report questionnaires, including the 26-item Eating Attitudes Test (EAT-26) and the Bulimic Investigatory Test Edinburgh (BITE). All the screen positives and an approximate 10\% random sample of the screen negatives were then interviewed using the Structured Clinical Interview for DSM-IV-TR Axis I Disorders Patient Version (SCID-I/P).

Results. The prevalence of individual EDs was much higher in the dance $[0.7 \%$ for anorexia nervosa (AN), 2.5\% for bulimia nervosa (BN) and 4.8\% for EDs, not otherwise specified (EDNOS)] than in the non-dance $(0 \cdot 1,1 \cdot 0$ and $0 \cdot 7 \%$ respectively) students. Multivariate logistic regression analyses revealed that being in the dance class, higher concern about body shape and lower family support were correlates of EDs for all students, whereas lower parental education level was associated with EDs only for non-dance students.

Conclusion. EDs were more prevalent in the weight-concerned subpopulation. Although AN is still rare, BN has emerged as a comparable prevalent disorder in Taiwan, as in Western countries.

\section{INTRODUCTION}

Eating disorders (EDs) comprise one of the most common psychiatric disorders to affect young women in the West, with a prevalence of

* Address for correspondence: Dr Wei J. Chen, Institute of Epidemiology, College of Public Health, National Taiwan University, 17 Xu-Zhou Road, Taipei 100, Taiwan.

(Email:weijen@ha.mc.ntu.edu.tw)
$0 \cdot 2-0 \cdot 7 \%$ for anorexia nervosa (AN) and around $1 \%$ for bulimia nervosa (BN) (Fairburn \& Beglin, 1990; Hsu, 1996; Hoek \& van Hoeken, 2003). Despite a growing body of literature reporting disordered eating in the general population or in subpopulations of athletes of non-Western countries in recent years (Pike \& Borovoy, 2004; Jennings et al. 2005; Okano et al. 2005; Lai et al. 2006), most of these studies 
were limited to questionnaire-based surveys or case-series studies and did not provide prevalence rates of clinical diagnoses (Tsai, 2000). In particular, few studies in non-Western societies investigated the epidemiological characteristics of BN (APA, 2000; Keel \& Klump, 2003).

For epidemiological surveys on disorders of relatively low prevalence, such as EDs, a two-phase survey is a useful alternative method of investigation (Pickles \& Dunn, 1995). In the first phase, a screening questionnaire such as the Eating Attitudes Test (EAT; Garner \& Garfinkel, 1979) for AN or the Bulimic Investigatory Test Edinburgh (BITE; Henderson \& Freeman, 1987) for BN is used to identify the at-risk population. The second phase consists of personal interviews of the at-risk population as well as of randomly selected subsamples of those scoring below the cut-off. A general rule is to select $100 \%$ of the screened positives for ethical reasons and only a portion of those who appear to be free of problems included in the second phase given the screening questionnaires can distinguish cases from noncases more than by chance (Shrout \& Newman, 1989). Despite their wide uses in Western populations, two-phase studies on EDs have several methodological limitations, including low response rate and the limited size of the groups interviewed (Fairburn \& Beglin, 1990; Hsu, 1996; Hoek \& van Hoeken, 2003). Most two-phase studies used the EAT to screen for all diagnostic categories of EDs; however, the ability of the EAT to identify $\mathrm{BN}$ has been questioned (Garfinkel \& Newman, 2001). For non-Western populations, only three studies to date have applied the two-phase design, with much lower prevalence rates being found in Hong Kong (Chen et al. 1993; Lee, 1993) and similar rates in Iran (Nobakht \& Dezhkam, 2000) as compared with those in Western countries.

Weight-related subcultural populations, such as dancers and athletes from particular sport disciplines, have been found to be at increased risk for EDs (Garner \& Garfinkel, 1978; Sundgot-Borgen \& Torstveit, 2004). Depending on the level of competition (Garner \& Garfinkel, 1980), ethnicity (Hamilton et al. 1985) and age (Dotti et al. 2002), the prevalence varied substantially, ranging from $1.8 \%$ to $8 \%$ for $\mathrm{AN}$ among ballet dancers (Garner \& Garfinkel, 1980; Szmukler et al. 1985; le Grange et al. 1994; Ravaldi et al. 2003; Ringham et al. 2006). However, there are some limitations regarding these studies, including lack of an appropriate control group (Szmukler et al. 1985; le Grange et al. 1994), low response rate (Szmukler et al. 1985), and the restriction to ballet dancers. Moreover, the majority of them focused solely on AN, especially in early studies.

In addition to the above-mentioned cultural factors (race and weight-related profession), some individual characteristics (such as weight and body image concern, negative affect, premorbid obesity, and sexual or physical abuse) and familial factors (such as parental obesity or psychopathology, parental discord, family interaction style, or dieting behavior of family members) were found to be correlates of EDs in studies in the general population (Fairburn et al. 1997, 1999; Halmi et al. 2000; Raffi et al. 2000; Webster \& Palmer, 2000; Barbara et al. 2002). Only a few studies have investigated the correlates of EDs among dancers, and those studies tended to have small sample sizes, ill-defined diagnoses, and used only univariate analysis (Garner \& Garfinkel, 1980; Hamilton et al. 1985; Garner et al. 1987; Thomas et al. 2005). Body image concern and competitive level were two factors frequently found to be associated with EDs in dancers. Other than these two, little is known about whether the cases of EDs in the dance population have common or distinct features with regard to those in the general population. We hypothesized that other than the common correlates of ED, overweight might make subjects in a dance class have a tendency to develop EDs under the sociocultural pressure to be thin.

Considering that EDs might be relatively rare among Asian general populations, we postulated that it might be more efficient to conduct a two-phase survey of EDs using dual screening instruments in both a nationally representative sample of high-risk people (e.g. female dance students) and a comparison group of female high-school students in Taiwan. The aims of this study were therefore (1) to investigate the prevalence rates of individual EDs, including $\mathrm{AN}$ and $\mathrm{BN}$, in both samples respectively, and (2) to evaluate the correlates of EDs in each sample. 


\section{METHOD}

\section{Participants and procedure}

There were two samples of subjects in this study: one from dance classes and the other from non-dance classes. The first sample consisted of all the senior high-school students who were enrolled in the gifted dance classes, started since 1981, in Taiwan. In total, there were 12 schools that had such special classes, with only one dance class in each grade at each school. In addition to the regular high-school curricula, these students received comprehensive dancing courses aimed at a professional career. After graduation, they went on to make up around $90 \%$ of the dance majors in colleges and universities and become the mainstream of professional dancers in Taiwan. Because the number of male students in the dance classes was small $(n=53)$, this study focused on females only $(n=655)$. For the second sample, nondance students at the same school or from a nearby school (some schools did not have regular high-school classes) were chosen as the comparison group. For each dance class, two classes of the same grade were randomly selected from the same or the nearby school $(n=1251)$.

Written informed consent was obtained from both students and their parents before the survey, which was conducted during the period from January 2003 to March 2003. Students who were willing to participate and were present at school on the day of the survey were asked to complete self-report questionnaires in class, including two screening instruments [the 26-item EAT (EAT-26) and BITE], as well as providing their current body height and weight, which are measured every semester for non-dance students in school and even more frequently (up to monthly) for dance students. The widely accepted cut-off point of the EAT $(\geqslant 20)$ (Garner \& Garfinkel, 1979) as well as a low body mass index $\left(\mathrm{BMI} ; \leqslant 18.5 \mathrm{~kg} / \mathrm{m}^{2}\right)$ was adopted as the criterion to screen for $\mathrm{AN}$, and a BITE symptom score above 15 or a severity score above 5 (Henderson \& Freeman, 1987) was defined as the criterion to screen for BN. All the students except one from the nondance class agreed to participate in the phaseone survey. After deleting those with incomplete questionnaire data (10 from the dance and
17 from the non-dance class) and absentees (32 from the dance and 52 from the nondance class), the response rate was found to be $93.6 \%(n=613)$ for the dance students and $94.4 \%(n=1181)$ for the non-dance students. All phase-one participants were then divided into four subgroups according to the results of dual screening: both criteria positive $\left(\mathrm{EAT}^{+} \mathrm{BITE}^{+}\right)$, the EAT criterion positive only $\left(\mathrm{EAT}^{+} \mathrm{BITE}^{-}\right)$, the BITE criterion positive only $\left(\mathrm{EAT}^{-} \mathrm{BITE}^{+}\right)$, and both criteria negative $\left(\mathrm{EAT}^{-} \mathrm{BITE}^{-}\right)$.

Phase-two participants consisted of all the screen positives for either the EAT or the BITE criteria and randomly selected $10 \%$ of those screen negatives for both criteria. The mean time interval between phase-one and phase-two assessments was $122 \pm 37$ days (range 77-198 days) due to logistic arrangements such as the enormous data processing load of phase-one screening questionnaires for 12 schools, and difficulties in scheduling a date that would not conflict with school events and allowed assessments for both dance and non-dance class students of the same school on the same day. Every phase-two participant was interviewed in person, measured for body weight, and also completed a self-administered questionnaire. The correlation between the self-reported body weight at phase one and that measured at phase two was high $(r=0.87, p<0 \cdot 001)$. Those absent on the day of interview were interviewed later by telephone, which was shown to be not different from face-to-face interviews in terms of diagnosis of EDs and a variety of psychiatric disorders (Keel et al. 2002). The response rates of phase-two interviews were $91.5 \%(248 / 271)$ for the screen positives and $92.5 \%(37 / 40)$ for the screen negatives for the dance students, and the corresponding figures were $87.7 \%(178 / 203)$ and $85 \cdot 3 \%(87 / 102)$ for the non-dance students. Reasons for nonresponse at phase-two interviews for the dance students included loss of contact by telephone $(n=23)$, refusal to be interviewed $(n=2)$ and logistic reasons $(n=1)$. The corresponding figures for non-dance students were 36,3 and 1 respectively. The study was approved by the Institutional Review Board of the National Taiwan University Hospital.

The numbers of participants in the four subgroups who received an interview at phase two 


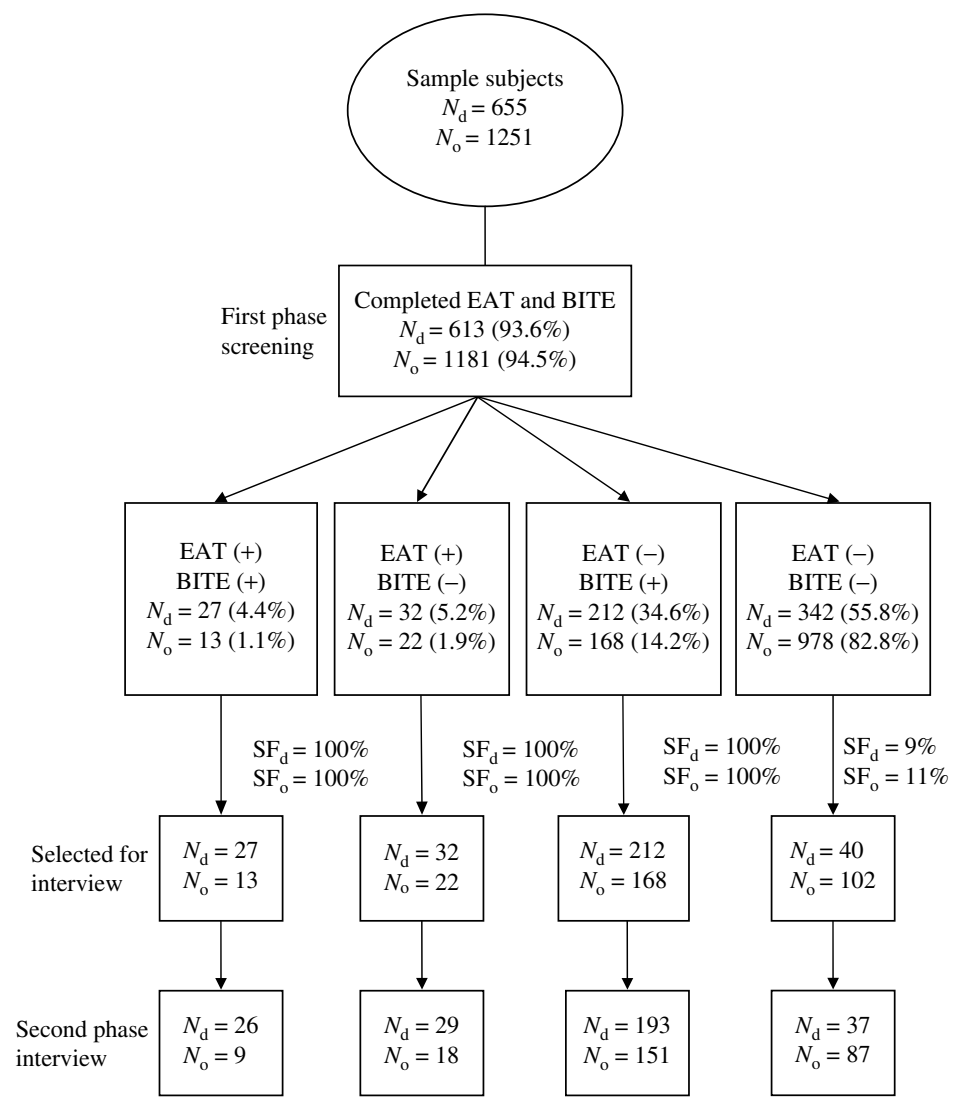

FIG. 1. Flow chart of the two-phase case identification of eating disorders among the female gifted dance and non-dance class students. EAT, Eating Attitudes Test; BITE, Bulimic Investigatory Test Edinburgh; $N_{\mathrm{d}}$, number of dance class students; $N_{\mathrm{o}}$, number of non-dance class students; $\mathrm{SF}_{\mathrm{d}}$, sampling fraction of phase-one dance class students; $\mathrm{SF}_{\mathrm{o}}$, sampling fraction of phase-one non-dance class students.

are shown in Fig. 1. The sampling weights of phase-two participants can be derived as the inverse of the proportion of being selected for phase-two interview. For example, the sampling weight for subgroup $\mathrm{EAT}^{+} \mathrm{BITE}^{+}$of the dance students was $1.04(27 / 26)$. The percentages of subjects receiving face-to-face interview and telephone interview were $83.5 \%(n=238)$ and $16.5 \%(n=47)$ respectively for the dance students, and $82 \cdot 6 \%(n=219)$ and $17 \cdot 4 \%(n=46)$ respectively for the non-dance students.

\section{Measurements}

Most self-reported questionnaires used in this study were administered in phase one, including the Body Shape Questionnaire (BSQ) and the Brief Symptom Rating Scale (BSRS), as well as demographic details, height, weight, and desired body weight, in addition to the screening questionnaire of the EAT and the BITE. In phase two, only the family APGAR (Adaptation, Partnership, Growth, Affection, and Resolve) scale was administered.

\section{EAT}

Eating problems were assessed using the EAT26 (Garner et al. 1982), an abbreviated version of the 40-item scale (EAT-40; Garner \& Garfinkel, 1979) with a high correlation $(r=$ 0.98). Each item is rated on a six-point Likert scale. For scoring, each extreme response in the 'anorexic' direction was scored as 3 points, the adjacent alternatives as 2 points and 1 point respectively, while the remaining three response alternatives in the nonanorexic direction were scored as 0 . The internal 
consistency (Cronbach's $\alpha=0 \cdot 81$ ) and testretest reliability (intra-class correlation reliability $=0.75$ ) of the Chinese version of EAT40 were demonstrated to be good in a previous study (Yang et al. 2004), and EAT-26 showed high correlation with EAT-40 $(r=0.91)$ (Chen, 1999).

\section{BITE}

This 36-item self-report measure consists of two subscales: the symptom scale (30 items) and the severity scale (six items). The former is rated with the binary response, while the latter is rated with the number corresponding to the frequency of bingeing or purging behaviors. The Chinese version of the BITE was found to have good internal consistency (Cronbach's $\alpha=0.95$ and 0.77 ) and test-retest reliability (intra-class correlation reliability 0.86 and 0.88 ) for the two scales (Tseng et al. 1997). Among a clinically obese population, a BITE symptom score of 20 had a sensitivity of $82.4 \%$, a specificity of $90.8 \%$, and a positive predictive value of $51.9 \%$ for binge eatingrelated disorders (Tseng et al. 2004).

\section{$B S Q$}

This 34-item questionnaire, rated on a six-point, frequency-based Likert scale, assesses feelings about body shape as well as behavioral and emotional consequences of such feelings (Cooper et al. 1987). The BSQ was translated into Chinese by a two-stage procedure by M.M.-C.T. and its internal consistency among the participating students $(n=1794)$ was found to be good (Cronbach's $\alpha=0 \cdot 96$ ). It was validated in a Taiwanese sample and found to discriminate well between subjects with EDs and normal female students.

\section{BSRS}

This 50-item self-rating scale was derived from Derogatis' Symptom Check List-90 (SCL-90; Derogatis et al. 1973). The BSRS has been demonstrated to have good reliability and construct validity in psychiatric and non-psychiatric out-patients as well as in community samples (Lee et al. 1990). Only the depression score and the General Severity Index (GSI; computed as the mean score of the 50 items of BSRS) score were reported in this study.

\section{Family APGAR}

This family function-screening questionnaire measures the participants' perception of five components of family function: adaptation, partnership, growth, affection, and resolve (Smilkstein, 1978; Chen et al. 1980). A higher score indicates a higher level of family support.

\section{Interview instrument and diagnosis}

The Structured Clinical Interview for DSMIV-TR Axis I Disorders Patient Version (SCID$\mathrm{I} / \mathrm{P}$; First et al. 2002) was used to evaluate ED diagnoses in the past year. The interview was conducted by one of two psychiatrists blind to the participants' screening results at each school site, with one psychiatrist (M.M.-C.T.) having experiences in treating patients with EDs for 15 years. In an inter-rater reliability evaluation of eight patients (including ED and non-ED cases) before the field survey, the $\kappa$ for EDs was 0.76 between the two psychiatrists. Those subjects who had clinically significant disorders of eating that did not meet the criteria for $\mathrm{AN}$ or $\mathrm{BN}$ were diagnosed as ED, not otherwise specified (EDNOS). Examples of EDNOS identified in this study included binge eating disorder (recurrent episodes of binge eating without inappropriate compensatory behaviors), menstruating AN (meeting the criteria for $\mathrm{AN}$ except for having regular menses), subthreshold $\mathrm{BN}$ (meeting the criteria for $\mathrm{BN}$ except for adequate frequency or duration), and purging disorder (purging regularly with the minimum frequency of once per month for 3 months, but without bingeing).

To minimize the possibility of missing cases of EDNOS (especially for purging disorders) by a negative response to the two probe questions for $\mathrm{AN}$ and $\mathrm{BN}$, we added one more screening question: 'Have you ever used any one of the following methods for weight maintenance or weight reduction, e.g. dieting, self-induced vomiting, taking laxatives, diuretics, or using suppositories?' Information about changes in eating habits, body weight or menstruation and the corresponding time for such changes was also requested.

In addition to the SCID-I/P, the interview covered personal history of sexual/physical abuse, as well as family history of parents' 
marital status, mental illness, obesity, and weight reduction practice in close relatives.

\section{Statistical analyses}

Participants with missing data on more than $10 \%$ of each scale (i.e. $\geqslant 3$ missing items on the EAT or $\geqslant 4$ missing items on the BITE) were excluded from the analyses. The rest of the missing data was imputed by means of the same class, grade and school subgroups. The weighted prevalence and its $95 \%$ confidence interval (CI) were derived by taking into account differential sampling weights in a two-phase design using the Taylor series method (Dunn et al. 1999) with the survey command SVYMEAN of the software package STATA (StataCorp, 2003). Weighted logistic regression analyses were performed to assess the correlates of EDs by means of the survey command svylogit. Considering the correlated nature of our data, we also applied the cross-sectional time series command XTreg to examine whether the mean differences in BMI and all the psychometric scores among the two populations still existed after controlling for the random effect of school.

\section{RESULTS}

\section{Characteristics of participants}

The mean age was $15 \cdot 8 \pm 0 \cdot 9$ years for the dance class and $15.9 \pm 0.9$ years for the non-dance class students. The other characteristics of phase-one participants are presented in Table 1. Compared with the non-dance group, the dance group had a lower proportion of grade 12 (due to higher dropping-out rates from the dance program for students of higher grade), higher parental educational level, greater height, less body weight, lower proportion of overweight, and older age for menarche. In terms of the screening questionnaire and related psychiatric symptom scales, the dance group had higher scores for the EAT, both the symptom and the severity scales of the BITE, the BSQ, and both the depression scores and GSI of the BSRS compared with the non-dance group. The differences between the two groups in BMI and all the psychometric scores remained significant after controlling for the random effect of school.

\section{Weighted 1-year prevalence of EDs}

On the basis of interview, only two cases, one with $\mathrm{BN}$ and the other with subthreshold $\mathrm{BN}$, were found to have developed binge eating or purging symptoms during the interval between the screening and interview and hence were not coded as having EDs for the subsequent analyses. The distribution of EDs among phase-two participants and the estimated prevalence are shown in Table 2. The prevalence of individual ED was much higher in the dance group $(0.7 \%$ for $\mathrm{AN}, 2 \cdot 5 \%$ for $\mathrm{BN}$, and $4.8 \%$ for EDNOS) than in the non-dance group $(0.1 \%$ for $A N$, $1.0 \%$ for $\mathrm{BN}$, and $0.7 \%$ for EDNOS). For all EDs together, the prevalence in the dance group $(8 \cdot 0 \%)$ was four times more than that in the non-dance group $(2.0 \%)$. If subjects with imputed data on the EAT or the BITE were deleted from analysis, the prevalence estimates changed only slightly, being $8.1 \%(95 \%$ CI $5 \cdot 6-10 \cdot 6)$ for the dance group and $2 \cdot 1 \%$ for the non-dance group $(95 \%$ CI $1 \cdot 2-3 \cdot 0)$.

The most frequently identified ED was either EDNOS (for the dance class students) or BN (for the non-dance class students), while AN was the least frequently identified. All the cases of AN were fat-phobic, that is none of them categorized as EDNOS due to non-fat-phobic.

Comparing the four subgroups, most cases were from those with $\mathrm{BITE}^{+}$, regardless of $\mathrm{EAT}^{+}$or $\mathrm{EAT}^{-}$. For the subgroup $\mathrm{EAT}^{+}$ BITE $^{-}$, only two participants were diagnosed as $\mathrm{AN}$ or subthreshold $\mathrm{AN}$, with restricting features for the dance class students. In terms of screening efficiency for any ED, combining the EAT with the BITE appeared to be better than using either one alone for the dance group, but the gain in efficiency was less obvious for the non-dance group, probably because of its low prevalence rate of AN.

\section{Correlates of EDs}

For the dance and non-dance students separately, the results of univariate logistic regression analyses revealed common and distinct correlates of EDs for the two groups (Table 3). When all the variables exhibiting a significant association in the univariate analyses were included for a multivariate logistic regression analysis, higher body shape concern and more psychological symptoms remained significantly associated with an increased risk of EDs for the dance students, with the effect of overweight, weight reduction practices of close relatives, and lower family support becoming borderline. 
Table 1. Basic data for phase-one participants: female dance and non-dance students

\begin{tabular}{|c|c|c|}
\hline & $\begin{array}{c}\text { Dance class } \\
(n=613)\end{array}$ & $\begin{array}{l}\text { Non-dance class } \\
\quad(n=1181)\end{array}$ \\
\hline \multicolumn{3}{|l|}{ Grade* } \\
\hline 10 & $226(36 \cdot 9)$ & $355(30 \cdot 1)$ \\
\hline 11 & $228(37 \cdot 2)$ & $426(36 \cdot 1)$ \\
\hline 12 & $159(25 \cdot 9)$ & $400(33 \cdot 9)$ \\
\hline \multicolumn{3}{|c|}{ Highest parental educational level (years) ${ }^{\mathrm{a} * *}$} \\
\hline$<9$ & $23(3 \cdot 8)$ & $58(5 \cdot 3)$ \\
\hline $9-12$ & $99(16 \cdot 5)$ & $209(19 \cdot 1)$ \\
\hline $12-16$ & $383(63 \cdot 7)$ & $570(52 \cdot 2)$ \\
\hline$\geqslant 16$ & $96(16 \cdot 0)$ & $256(23 \cdot 4)$ \\
\hline Menstruation not started yet & $1(0 \cdot 2)$ & $3(0 \cdot 3)$ \\
\hline Overweight $\left(\mathrm{BMI} \geqslant 23 \mathrm{~kg} / \mathrm{m}^{2}\right)^{* * *}$ & $11(1 \cdot 8)$ & $181(15 \cdot 4)$ \\
\hline Weight $(\mathrm{kg})^{\mathrm{b} * *}$ & $50 \cdot 0(5 \cdot 2)$ & $52 \cdot 1(8 \cdot 0)$ \\
\hline Height $(\mathrm{cm})^{\mathrm{c} *}$ & $160 \cdot 6(5 \cdot 1)$ & $159 \cdot 8(5 \cdot 4)$ \\
\hline BMI $\left(\mathrm{kg} / \mathrm{m}^{2}\right)^{* *}$ & $19 \cdot 4(1 \cdot 6)$ & $20 \cdot 4(2 \cdot 8)$ \\
\hline Menarche (years) ${ }^{\mathrm{d} * *}$ & $13 \cdot 0(1 \cdot 2)$ & $12 \cdot 6(1 \cdot 2)$ \\
\hline EAT score** & $17 \cdot 2(10 \cdot 1)$ & $11 \cdot 2(8 \cdot 4)$ \\
\hline BITE score** & $14 \cdot 3(7 \cdot 3)$ & $9 \cdot 7(6 \cdot 1)$ \\
\hline Symptom score** & $11 \cdot 4(5 \cdot 2)$ & $8 \cdot 4(4 \cdot 8)$ \\
\hline Severity score** & $2 \cdot 9(3 \cdot 2)$ & $1 \cdot 3(2 \cdot 1)$ \\
\hline Body Shape Questionnaire score** & $78 \cdot 4(35)$ & $56 \cdot 9(34 \cdot 6)$ \\
\hline \multicolumn{3}{|l|}{ Brief Symptom Rating Scale } \\
\hline Depression score** & $1 \cdot 2(0 \cdot 9)$ & $1 \cdot 1(0 \cdot 9)$ \\
\hline General Severity Index score** & $1 \cdot 2(0 \cdot 7)$ & $1 \cdot 0(0 \cdot 7)$ \\
\hline
\end{tabular}

Values are $n(\%)$ or mean (S.D.).

S.D., Standard deviation; BMI, body mass index; EAT, Eating Attitudes Test; BITE, Bulimic Investigatory Test Edinburgh.

a Data missing for 12 students for the dance class and 88 for the non-dance class.

b Data missing for 2 students for the dance class and 18 for the non-dance class.

${ }^{c}$ Data missing for 1 student for the dance class and 18 for the non-dance class.

d Data missing for 28 students for the dance class and 93 for the non-dance class.

$* p<0 \cdot 01, * * p<0 \cdot 001$ for comparing the dance with the non-dance students.

Meanwhile, lower parental education, higher body shape concern, and lower family support remained significantly associated with an increased risk for EDs in the non-dance students. Overweight, more psychological symptoms, and weight reduction practices of close relatives were associated with EDs only for the dance students, whereas lower parental education was associated with EDs only for the non-dance students.

To increase the power for detecting the correlates of EDs, two groups together were subjected to multivariate logistic regression analyses, including the variable class type along with six variables exhibiting a significant association with EDs in either group as well as three interaction terms between class type and the three distinctive correlates. All variables with a $p>0 \cdot 1$ were deleted from the model in a backward manner. It turned out that lower parental education and the interaction between parental education and class type were associated with an increased risk for EDs in addition to dance class, higher body shape concern, and lower family support (Table 4). The interaction between parental education and class type remained significant in the final model, that is the association of parental education with EDs depended on class type. For the non-dance students, lower parental education was associated with a higher risk for EDs [odds ratio $(\mathrm{OR})=$ $4 \cdot 10)$ ], whereas for the dance students, lower parental education was not associated with an increased risk for EDs $[\mathrm{OR}=\exp (1 \cdot 41-1 \cdot 60)=$ $0 \cdot 83,95 \%$ CI $0 \cdot 51-2 \cdot 51]$.

\section{DISCUSSION}

On the basis of a two-phase survey in a nationally representative sample of dance class students as well as a comparison sample of nondance class students, this study found that the prevalence of EDs in dance class students was higher than that in non-dance class students in 
Table 2. Distribution of eating disorders (EDs) among phase-two participants and the estimated prevalence

\begin{tabular}{|c|c|c|c|c|c|}
\hline & $\begin{array}{c}\mathrm{EAT}^{+} \mathrm{BITE}^{+} \\
n(\%)\end{array}$ & $\begin{array}{c}\mathrm{EAT}^{+} \mathrm{BITE}^{-} \\
n(\%)\end{array}$ & $\begin{array}{c}\mathrm{EAT}^{-} \mathrm{BITE}^{+} \\
n(\%)\end{array}$ & $\begin{array}{c}\mathrm{EAT}^{-} \mathrm{BITE}^{-} \\
n(\%)\end{array}$ & $\begin{array}{c}\text { Estimated prevalence } \\
\quad p(95 \% \mathrm{CI})\end{array}$ \\
\hline Dance students & $n=26$ & $n=29$ & $n=193$ & $n=37$ & \\
\hline Sampling weight & $27 / 26=1 \cdot 04$ & $32 / 29=1 \cdot 10$ & $212 / 193=1 \cdot 10$ & $342 / 37=9 \cdot 24$ & \\
\hline AN & $2(7 \cdot 6)$ & $1(3 \cdot 4)$ & $1(0 \cdot 5)$ & $0(0)$ & $0 \cdot 7(0 \cdot 0-1 \cdot 4)$ \\
\hline $\mathrm{BN}$ & $2(7 \cdot 6)$ & $0(0)$ & $12(6 \cdot 2)$ & $0(0)$ & $2 \cdot 5(1 \cdot 2-3 \cdot 8)$ \\
\hline EDNOS & $6(23 \cdot 0)$ & $1(3 \cdot 4)$ & $20(10 \cdot 3)$ & $0(0)$ & $4 \cdot 8(3 \cdot 1-6 \cdot 5)$ \\
\hline Binge eating disorder & 0 & 0 & 2 & 0 & \\
\hline Menstruating AN & 4 & 1 & 1 & 0 & \\
\hline Subthreshold BN & 1 & 0 & 9 & 0 & \\
\hline Purging disorder & 1 & 0 & 8 & 0 & \\
\hline All eating disorders & $10(38 \cdot 5)$ & $2(6 \cdot 8)$ & $33(17 \cdot 0)$ & $0(0)$ & $8 \cdot 0(5 \cdot 9-11 \cdot 1)$ \\
\hline Non-dance students & $n=9$ & $n=18$ & $n=151$ & $n=87$ & \\
\hline Sampling weight & $13 / 9=1.44$ & $22 / 18=1 \cdot 22$ & $168 / 151=1 \cdot 11$ & $978 / 87=11 \cdot 24$ & \\
\hline AN & $1(11 \cdot 1)$ & $0(0)$ & $0(0)$ & $0(0)$ & $0 \cdot 1(0 \cdot 0-0 \cdot 4)$ \\
\hline $\mathrm{BN}$ & $1(11 \cdot 1)$ & $0(0)$ & $11(6 \cdot 5)$ & $0(0)$ & $1 \cdot 0(0 \cdot 5-1 \cdot 8)$ \\
\hline EDNOS & $0(0)$ & $0(0)$ & $8(4 \cdot 7)$ & $0(0)$ & $0 \cdot 7(0 \cdot 2-1 \cdot 3)$ \\
\hline Binge eating disorder & 0 & 0 & 2 & 0 & \\
\hline Menstruating AN & 0 & 0 & 0 & 0 & \\
\hline Subthreshold BN & 0 & 0 & 5 & 0 & \\
\hline Purging disorder & 0 & 0 & 1 & 0 & \\
\hline All eating disorders & $2(22 \cdot 2)$ & $0(0)$ & $19(11 \cdot 3)$ & $0(0)$ & $2 \cdot 0(1 \cdot 2-2 \cdot 9)$ \\
\hline
\end{tabular}

AN, Anorexia nervosa; BN, bulimia nervosa; EAT, Eating Attitudes Test; BITE, Bulimic Investigatory Test Edinburgh; EDNOS, eating disorder, not otherwise specified.

Table 3. Univariate and multivariate logistic regression analysis of correlates for eating disorders

\begin{tabular}{|c|c|c|c|c|}
\hline \multirow[b]{2}{*}{ Variables } & \multicolumn{2}{|c|}{ Dance class } & \multicolumn{2}{|c|}{ Non-dance class } \\
\hline & Univariate analysis & Multivariate analysis & Univariate analysis & Multivariate analysis \\
\hline \multicolumn{5}{|l|}{ Grade (10th grade as the reference) } \\
\hline 11 & $0 \cdot 87(0 \cdot 37-2 \cdot 03)$ & - & $2 \cdot 26(0 \cdot 65-7 \cdot 84)$ & - \\
\hline 12 & $1 \cdot 87(0 \cdot 76-4 \cdot 58)$ & - & $2 \cdot 57(0.68-9 \cdot 68)$ & - \\
\hline Overweight (BMI $\geqslant 23$ kg/m²) & $10 \cdot 04(2 \cdot 59-39 \cdot 02) * * * *$ & $4 \cdot 37(0 \cdot 91-20 \cdot 89)^{*}$ & $1.26(0.33-4 \cdot 86)$ & - \\
\hline Parental education ( $<12$ years) & $1 \cdot 13(0 \cdot 46-2 \cdot 77)$ & - & $5 \cdot 31(1 \cdot 95-14 \cdot 45)^{* * *}$ & $4.07(1.38-11 \cdot 99)^{* *}$ \\
\hline Parental marriage (disruption) & $1.92(0.66-5.65)$ & - & $1.93(0 \cdot 48-7 \cdot 85)$ & - \\
\hline \multicolumn{5}{|l|}{ Previous history } \\
\hline Overweight & $2 \cdot 17(0 \cdot 76-6 \cdot 15)$ & - & $1.86(0.64-5 \cdot 39)$ & - \\
\hline Sexual abuse & $0.97(0 \cdot 17-5 \cdot 68)$ & - & $3 \cdot 21(0 \cdot 28-36 \cdot 31)$ & - \\
\hline Body Shape Questionnaire score & $1.03(1.02-1 \cdot 04)^{* * * *}$ & $1 \cdot 02(1 \cdot 00-1 \cdot 03)^{* *}$ & $1 \cdot 03(1 \cdot 02-1 \cdot 05)^{* * * * *}$ & $1.04(1.03-1.06)^{* * * *}$ \\
\hline GSI score of the BSRS & $2 \cdot 89(2 \cdot 01-4 \cdot 16)^{* * *}$ & $1.73(1.04-2.88) * *$ & $2.61(1.67-4.08)^{* * * * *}$ & $0.83(0.47-1 \cdot 49)$ \\
\hline \multicolumn{5}{|l|}{ Family history } \\
\hline Mental illness & $2 \cdot 33(0 \cdot 74-7 \cdot 31)$ & - & $3 \cdot 61(1 \cdot 11-11 \cdot 71)^{* *}$ & $1.39(0.41-4.67)$ \\
\hline Obesity & $1 \cdot 55(0 \cdot 74-3 \cdot 26)$ & - & $1 \cdot 51(0 \cdot 55-4 \cdot 15)$ & - \\
\hline $\begin{array}{l}\text { Weight reduction practices } \\
\text { of close relatives }\end{array}$ & $2 \cdot 03(0 \cdot 97-4 \cdot 26)^{*}$ & $1.91(0 \cdot 90-4 \cdot 04)^{*}$ & $0 \cdot 92(0 \cdot 30-2 \cdot 77)$ & - \\
\hline Family APGAR score & $0.87(0.78-0.97)^{* *}$ & $0 \cdot 91(0 \cdot 82-1 \cdot 00)^{*}$ & $0 \cdot 77(0 \cdot 67-0 \cdot 89)^{* * * *}$ & $0 \cdot 80(0 \cdot 70-0 \cdot 92)^{* * *}$ \\
\hline
\end{tabular}

Values are odds ratios (95\% confidence intervals).

BMI, Body mass index; GSI, General Severity Index; BSRS, Brief Symptom Rating Scale; APGAR, Adaptation, Partnership, Growth, Affection, and Resolve.

$* p<0 \cdot 1, * * p<0 \cdot 05, * * * p<0 \cdot 01, * * * * p<0 \cdot 001$, for testing the null hypothesis $\mathrm{H}_{0}$ : odds ratio $=1 \cdot 0$.

Taiwan, and the order of frequency for individual ED was parallel to that in the general population but distinct from the results of earlier studies in ballet dancers of Western countries. To our knowledge, this is the first study examining EDs in gifted dance students in
non-Western countries. As expected, we found that the prevalence of $\mathrm{AN}$ in dance class or nondance class students was lower than that for its counterparts in Western countries. However, the prevalence of $\mathrm{BN}$ in this study was substantially higher than that of AN, regardless of the 
Table 4. Multivariate logistic regression analysis of correlates for eating disorders with both the dance and non-dance class students together

\begin{tabular}{|c|c|c|c|c|}
\hline Variables & Parameter estimate & S.E. & $p$ & OR $(95 \% \mathrm{CI})$ \\
\hline Dance class & $1 \cdot 29$ & $0 \cdot 41$ & $0 \cdot 002$ & $3.65(1.62-8.23) * * *$ \\
\hline Parental education $(<12$ years) & $1 \cdot 41$ & $0 \cdot 51$ & $0 \cdot 006$ & $4 \cdot 10(1 \cdot 51-11 \cdot 1)^{* * *}$ \\
\hline Body Shape Questionnaire score & $0 \cdot 03$ & $0 \cdot 00$ & $0 \cdot 000$ & $1.03(1.02-1.04)^{* * * *}$ \\
\hline Family APGAR score & $-0 \cdot 15$ & $0 \cdot 04$ & $0 \cdot 000$ & $0.86(0.79-0.94) * * * *$ \\
\hline Parental education $\times$ class type & -1.60 & $0 \cdot 73$ & $0 \cdot 027$ & $0.20(0.05-0.85)^{* *}$ \\
\hline Overweight $\times$ class type & $1 \cdot 50$ & $0 \cdot 81$ & $0 \cdot 062$ & $4.50(0.92-21.87)^{*}$ \\
\hline
\end{tabular}

S.E., Standard error; OR, odds ratio; CI, confidence interval; APGAR, Adaptation, Partnership, Growth, Affection, and Resolve.

$* p<0 \cdot 1, * * p<0 \cdot 05, * * * p<0 \cdot 01, * * * * p<0 \cdot 001$, for testing the null hypothesis $\mathrm{H}_{0}$ : odds ratio $=1 \cdot 0$.

dance or non-dance group. The prevalence of BN for non-dance class students was even comparable to that of Western countries $(1 \%)$ (Fairburn \& Beglin, 1990; Hoek \& van Hoeken, 2003).

Our finding that EDNOS was more prevalent than any other EDs in the dance group was consistent with more recent Western studies (le Grange et al. 1994; Abraham, 1996; Ravaldi et al. 2003; Ringham et al. 2006). However, the prevalence rates were much lower than those of their counterparts in Western ballet dance groups. One reason might be the lower demand on body weight in Taiwanese dance students as they did not restrict their dance curriculum to ballet but also took courses in Chinese folk dance, martial art or jazz. Another possible reason is the younger age in our sample of highschool students as compared with the ballet dancers of college students, as the risk of EDs increased with age (Dotti et al. 2002). Intriguingly, the unexpected lower prevalence of EDNOS compared with that of $\mathrm{BN}$ in the nondance group might be accounted for by their lower exposure to weight-related stimuli as the non-dance students were kept on an extremely tight academic schedule in preparation for college entrance.

The finding that $\mathrm{BN}$ was more prevalent than AN in this study is similar to that of Western countries (Keel \& Klump, 2003) and a recent study in Iran (Nobakht \& Dezhkam, 2000), but opposite to that observed in Hong Kong (Lee et al. 1992) or Japan (Nakamura et al. 2000). The study in Japan was based on doctors' reports rather than on a population survey. Weight concerns and Western influence were consistent features in all cases of $\mathrm{BN}$, but might not be present in some cases of AN (Keel \& Klump, 2003). Unlike the atypical features found in some AN patients in non-Western society (Lee \& Hsu, 1993), all the cases of AN in our samples were fat-phobic. Our findings of a consistently low prevalence of $\mathrm{AN}$ but a prevalence rate of $\mathrm{BN}$ equivalent to that of Western countries provide further support that $\mathrm{BN}$ is more susceptible to the Western influence than AN.

The common psychosocial correlates of EDs found in this study, including enrolment in a dance class, greater concern with body shape and lower family support, are consistent with other studies (Garner \& Garfinkel, 1980; Waller et al. 1989; Shisslak et al. 1990; Killen et al. 1994). Among the three distinct correlates for the dance class students, overweight and more psychological symptoms are probably accounted for by the tension encountered in keeping body shape for this subpopulation. Recent neuroendocrinological studies have found that the brain machinery responsible for food intake and body weight can modulate emotion and motivated behavior as well (Kishi \& Elmquist, 2005). Mood disturbances have been found to be associated with EDs in both the general population (Johnson-Sabine et al. 1988; Patton et al. 1990, 1999) and dancers (Garner \& Garfinkel, 1980; Ravaldi et al. 2003), although one study found the association in the non-dancer but not in the dancer group (Holderness et al. 1994), probably because of its recruitment strategy for young adult women at risk for decreased bone density. Overweight among the dance class students might therefore be a consequence of maladaptation to the prevailing cultural pressure to be thin. Another 
possibility is that the dance class students with EDs might be influenced by a family environment in which weight reduction was prevalent (Klump et al. 2001), which is the third distinct correlate for this subpopulation. This is compatible with the finding that $\mathrm{BN}$ had a substantial contribution from familial influences (Kendler et al. 1995). From the practical point of view, our findings indicate that dance class students with overweight or emotional disturbances should be the focus of prevention or early detection of EDs.

A distinct correlate of EDs for the non-dance class students is lower parental education. Although EDs were initially reported to be most common among upper classes, the observation was not supported by later epidemiological surveys (Gard \& Freeman, 1996). Another reason for the association of lower parental education with EDs might be that the predominant diagnosis found in this study was $\mathrm{BN}$ rather than AN.

Limitations of this study should be kept in mind in interpreting our results. First, for those students who were absent from school on the screening day, we missed information about their ED status. Second, there was time lag between the date of screening and the date of interviewing. For those participants who developed binge eating or purging symptoms during the interval between the screening and the interview, we did not code them as cases to minimize the impact of this time lag. However, as eating-related symptoms were shown to have good inter-rater (Cantwell et al. 1997) and test-retest reliability (Rizvi et al. 2000), the chance of participants' failure to report these symptoms was probably negligible. Third, because of the limited number of cases in each diagnostic category and lack of consensus in the literature regarding the discrimination between $\mathrm{AN}$ and $\mathrm{BN}$ in terms of risk factors (StriegelMoore, 1997; Jacobi et al. 2004), the analyses of psychosocial correlates were conducted only for a broad diagnostic category including $\mathrm{AN}, \mathrm{BN}$ and EDNOS. Finally, the body weight used in the screening was based on self-report only. Nevertheless, its impact on the estimation of EDs might be minimal because the self-reported weight had a high correlation with the measured one and our diagnoses of EDs were based on inperson interviews.
In conclusion, this study demonstrated that EDs were more prevalent in the weightconcerned subpopulation. BN was more prevalent than AN among Taiwanese high-school female students, and was at a similar rate to that found in Western countries. Despite the scarcity of literature with regard to $\mathrm{BN}$ among nonWestern populations, we should be aware that $\mathrm{BN}$ has now emerged as a prevalent disorder in non-Western countries such as Taiwan.

\section{ACKNOWLEDGMENTS}

This study was sponsored by research grants from the National Science Council, Taiwan (NSC91-2413-H-134-021 and NSC92-2314-B002-293). We thank all of the school teachers, students and personnel for their participation and assistance in this project.

\section{DECLARATION OF INTEREST}

None.

\section{REFERENCES}

Abraham, S. (1996). Characteristics of eating disorders among young ballet dancers. Psychopathology 29, 223-229.

APA (2000). Diagnostic and Statistical Manual of Mental Disorders (4th edn, text revision) (DSM IV-TR). American Psychiatric Association: Washington, DC

Barbara, L., Christine, J. S., Iris, R. \& Martin, H. S. (2002) Characteristics of inpatient weight gain in adolescent anorexia nervosa: relation to speed of relapse and re-admission. European Eating Disorders Review 10, 22-40.

Cantwell, D. P., Lewinsohn, P. M., Rohde, P. \& Seeley, J. R. (1997) Correspondence between adolescent report and parent report of psychiatric diagnostic data. Journal of the American Academy of Child and Adolescent Psychiatry 36, 610-619.

Chen, C. N., Wong, J., Lee, N., Chan-Ho, M. W., Lau, J. T. \& Fung, M. (1993). The Shatin community mental health survey in Hong Kong: II. Major findings. Archives of General Psychiatry 50, 125-133.

Chen, Y. C., Hsu, C. C. \& Hsu, S. H. (1980). A preliminary study of the family APGAR index [in Chinese with English abstract]. Acta Pediatrica Sinica 21, 210-227.

Chen, Y. H. (1999). Epidemiological Study of Eating Behavior and Psychosocial Correlates Among Adolescents [in Chinese with English abstract]. Unpublished Master's Thesis, Institute of Epidemiology, College of Public Health, National Taiwan University, Taipei, Taiwan.

Cooper, P. J., Tayor, M. J., Cooper, Z. \& Fairburn, C. G. (1987). The development and validation of the Body Shape Questionnaire. International Journal of Eating Disorders 6, 485-494.

Derogatis, L. R., Lipman, R. S. \& Covi, L. (1973). The SCL-90: an outpatient psychiatric rating scale-preliminary report. Psychopharmacology Bulletin 9, 13-28.

Dotti, A., Fioravanti, M., Balotta, M., Tozzi, F., Cannella, C. \& Lazzari, R. (2002). Eating behavior of ballet dancers. Eating and Weight Disorders 7, 60-67. 
Dunn, G., Pickles, A., Tansella, M. \& Vazquez-Barquero, J. L. (1999). Two-phase epidemiological surveys in psychiatric research. British Journal of Psychiatry 174, 95-100.

Fairburn, C. \& Beglin, S. (1990). Studies of the epidemiology of bulimia nervosa. American Journal of Psychiatry 147, 401-408.

Fairburn, C. G., Cooper, Z., Doll, H. \& Welch, S. L. (1999). Risk factors for anorexia nervosa: three integrated case-control comparisons. Archives of General Psychiatry 56, 468-476.

Fairburn, C. G., Welch, S. L., Doll, H. A. \& O'Conner, M. E. (1997). Risk factors for bulimia nervosa: a community-based case-control study. Archives of General Psychiatry 54, 509-517.

First, M. B., Spitzer, R., Gibbon, M. \& Williams, J. B. W. (2002). Structured Clinical Interview for DSM-IV-TR Axis I Disorders. Biometrics Research Department, New York State Psychiatric Institute: New York.

Gard, M. C. \& Freeman, C. P. (1996). The dismantling of a myth: a review of eating disorders and socioeconomic status. International Journal of Eating Disorders 20, 1-12.

Garfinkel, P. E. \& Newman, A. (2001). The eating attitudes test: twenty-five years later. Eating and Weight Disorders 6, 1-24.

Garner, D. M. \& Garfinkel, P. E. (1978). Sociocultural factors in anorexia nervosa. Lancet $\mathbf{2}, 674$.

Garner, D. M. \& Garfinkel, P. E. (1979). The eating attitudes test: an index of the symptoms of anorexia nervosa. Psychological Medicine 9, 273-279.

Garner, D. M. \& Garfinkel, P. E. (1980). Socio-cultural factors in the development of anorexia nervosa. Psychological Medicine 10 647-656.

Garner, D. M., Garfinkel, P. E., Rockert, W. \& Olmsted, M. (1987). A prospective study of eating disturbances in the ballet. Psychotherapy and Psychosomatics 48, 170-175.

Garner, D. M., Olmsted, M. P., Bohr, Y. \& Garfinkel, P. E. (1982). The eating attitudes test: psychometric features and clinical correlates. Psychological Medicine 12, 871-878.

Halmi, K. A., Sunday, S. R., Strober, M., Kaplan, A. S., Woodside, D. B., Fichter, M. M., Treasure, J., Berrettini, W. H. \& Kaye, W. H. (2000). Perfectionism in anorexia nervosa: variation by clinical subtype, obsessionality, and pathological eating behavior. American Journal of Psychiatry 157, 1799-1805.

Hamilton, L. H., Brooks-Gunn, J. \& Warren, M. P. (1985) Sociocultural influences on eating disorders in professional female ballet dancers. International Journal of Eating Disorders 4, 465-477.

Henderson, M. \& Freeman, C. P. L. (1987). A self-rating scale for bulimia. The 'BITE'. British Journal of Psychiatry 150, $18-24$

Hoek, H. W. \& van Hoeken, D. (2003). Review of the prevalence and incidence of eating disorders. International Journal of Eating Disorders 34, 383-396.

Holderness, C. C., Brooks-Gunn, J. \& Warren, M. P. (1994). Eating disorders and substance use: a dancing vs a nondancing population. Medicine and Science in Sports and Exercise 26, 297-302.

Hsu, L. K. G. (1996). Epidemiology of the eating disorders. Psychiatric Clinics of North America 19, 681-700.

Jacobi, C., Hayward, C., de Zwaan, M., Kraemer, H. C. \& Agras, W. S. (2004). Coming to terms with risk factors for eating disorders: application of risk terminology and suggestions for a general taxonomy. Psychological Bulletin 130, 19-65.

Jennings, P. S., Forbes, D., McDermott, B., Juniper, S. \& Hulse, G. (2005). Acculturation and eating disorders in Asian and Caucasian Australian adolescent girls. Psychiatry and Clinical Neurosciences 59, 56-61.

Johnson-Sabine, E., Wood, K., Patton, G., Mann, A. \& Wakeling, A. (1988). Abnormal eating attitudes in schoolgirls - a prospective epidemiological study: factors associated with abnormal response on screening questionnaires. Psychological Medicine 18, 615-622.

Keel, P. K., Crow, S., Davis, T. L. \& Mitchell, J. E. (2002). Assessment of eating disorders: comparison of interview and questionnaire data from a long-term follow-up study of bulimia nervosa. Journal of Psychosomatic Research 53, 1043 1047

Keel, P. K. \& Klump, K. L. (2003). Are eating disorders culturebound syndromes? Implications for conceptualizing their etiology. Psychological Bulletin 129, 747-769.

Kendler, K. S., Walters, E. E., Neale, M. C., Kessler, R. C., Heath, A. C. \& Eaves, L. J. (1995). The structure of the genetic and environment risk factors for six major psychiatric disorders in women. Phobia, generalized anxiety disorder, panic disorder, bulimia, major depression, and alcoholism. Archives of General Psychiatry 52, 374-383.

Killen, J. D., Taylor, C. B., Hayward, C., Wilson, D. M., Haydel, K. F., Hammer, L. D., Simmonds, B., Robinson, T. N., Litt, I. \& Varady, A. (1994). Pursuit of thinness and onset of eating disorder symptoms in a community sample of adolescent girls: a three-year prospective analysis. International Journal of Eating Disorders $\mathbf{1 6}$, 227-238.

Kishi, T. \& Elmquist, J. K. (2005). Body weight is regulated by the brain: a link between feeding and emotion. Molecular Psychiatry 10, $132-146$

Klump, K. L., Ringham, R., Marcus, M. D. \& Kaye, W. (2001). A family history/family study investigation of eating disorder risk in ballet dancers: evidence of gene-environment combinations? Paper presented at the Annual Meeting of the Eating Disorders Research Society, Albuquerque, NM.

Lai, B. P. Y., Tang, C. S. K. \& Tse, W. K. I. (2006). A longitudinal study investigating disordered eating during the transition to motherhood among Chinese women in Hong Kong. International Journal of Eating Disorders 39, 303-311.

le Grange, D., Tibbs, J. \& Noakes, T. D. (1994). Implications of a diagnosis of anorexia nervosa in a ballet school. International Journal of Eating Disorders 15, 369-376.

Lee, M. B., Lee, Y. J., Yen, L. L., Lin, M. H. \& Lue, B. H. (1990) Reliability and validity of using a brief psychiatric symptom rating scale in clinical practice. Journal of the Formosan Medical Association 89, 1081-1087.

Lee, S. (1993). How abnormal is the desire for slimness? A survey of eating attitudes and behavior among Chinese undergraduates in Hong Kong. Psychological Medicine 23, 437-451.

Lee, S., Hsu, L. K. \& Wing, Y. K. (1992). Bulimia nervosa in Hong Kong Chinese patients. British Journal of Psychiatry 161, 545-551.

Lee, S. \& Hsu, L. K. G. (1993). Fat phobic and non-fat phobic anorexia nervosa: a comparative study of 70 Chinese patients in Hong Kong. Psychological Medicine 23, 999-1017.

Nakamura, K., Yamamoto, M., Yamazaki, O., Kawashima, Y., Muto, K., Someya, T., Sakurai, K. \& Nozoe, S. (2000). Prevalence of anorexia nervosa and bulimia nervosa in a geographically defined area in Japan. International Journal of Eating Disorders 28 173-180.

Nobakht, M. \& Dezhkam, M. (2000). An epidemiological study of eating disorders in Iran. International Journal of Eating Disorders 28, 265-271.

Okano, G., Holmes, R. A., Mu, Z., Yang, P., Lin, Z. \& Nakai, Y. (2005). Disordered eating in Japanese and Chinese female runners, rhythmic gymnasts and gymnasts. International Journal of Sports Medicine 26, 486-491

Patton, G. C., Johnson-Sabine, E., Wood, K., Mann, A. H. \& Wakeling, A. (1990). Abnormal eating attitudes in London schoolgirls - a prospective epidemiological study: outcome at twelve month follow-up. Psychological Medicine 20, 383-394.

Patton, G. C., Selzer, R., Coffey, C., Carlin, J. B. \& Wolfe, R. (1999). Onset of adolescent eating disorders: population based cohort study over 3 years. British Medical Journal 318 $765-768$.

Pickles, A. \& Dunn, G. (1995). Screening for stratification in twophase (two-stage) epidemiological surveys. Statistical Methods in Medical Research 4, 73-89.

Pike, K. M. \& Borovoy, A. (2004). The rise of eating disorders in Japan: issues of culture and limitations of the model of "westernization'. Culture, Medicine and Psychiatry 28, 493-531. 
Raffi, A. R., Rondini, M., Grandi, S. \& Fava, G. A. (2000). Life events and prodromal symptoms in bulimia nervosa. Psychological Medicine 30, 727-731.

Ravaldi, C., Vannacci, A., Zucchi, T., Mannucci, E., Cabras, P. L., Boldrini, M., Murciano, L., Rotella, C. M. \& Ricca, V. (2003). Eating disorders and body image disturbances among ballet dancers, gymnasium users and body builders. Psychopathology 36, 247-254.

Ringham, R., Klump, K., Kaye, W., Stone, D., Libman, S., Stowe, S. \& Marcus, M. (2006). Eating disorder symptomatology among ballet dancers. International Journal of Eating Disorders 39, 503-508.

Rizvi, S. L., Peterson, C. B., Crow, S. J. \& Agras, W. S. (2000) Test-retest reliability of the eating disorder examination. International Journal of Eating Disorders 28, 311-316.

Shisslak, C. M., McKeon, R. T. \& Crago, M. (1990). Family dysfunction in normal weight bulimic and bulimic anorexic families. Journal of Clinical Psychology 46, 185-189.

Shrout, P. E. \& Newman, S. C. (1989). Design of two-phase prevalence surveys of rare disorders. Biometrics 45, 549-555.

Smilkstein, G. (1978). The family APGAR: a proposal for a family function test and its use by physicians. Journal of Family Practice 6, 1231-1239.

StataCorp (2003). Stata Statistical Software: Release 8.0. Stata Corporation, College Station: TX.

Striegel-Moore, R. H. (1997). Risk factors for eating disorders. Annals of the New York Academy of Sciences 817, 98-109.

Sundgot-Borgen, J. \& Torstveit, M. K. (2004). Prevalence of eating disorders in elite athletes is higher than in the general population. Clinical Journal of Sport Medicine 14, 25-32.
Szmukler, G. I., Eisler, I., Gillies, C. \& Hayward, M. E. (1985). The implications of anorexia nervosa in a ballet school. Journal of Psychiatric Research 19, 177-181.

Thomas, J. J., Keel, P. K. \& Heatherton, T. F. (2005). Disordered eating attitudes and behaviors in ballet students: examination of environmental and individual risk factors. International Journal of Eating Disorders 38, 263-268.

Tsai, G. (2000). Eating disorders in the Far East. Eating and Weight Disorders 5, 183-197.

Tseng, M. C., Lee, M. B., Chen, S. Y., Lee, Y. J., Lin, K. H., Chen, P. R. \& Lai, J.S. (2004). Response of Taiwanese obese binge eaters to a hospital-based weight reduction program. Journal of Psychosomatic Research 57, 279-285.

Tseng, M. C., Lee, M. B. \& Lee, Y. J. (1997). Reliability and validity of Chinese version of the Bulimic Investigatory Test [in Chinese with English abstract]. Taiwanese Journal of Psychiatry 11, 141155 .

Waller, G., Calam, R. \& Slade, P. (1989). Eating disorders and family interaction. British Journal of Clinical Psychology 28, 285286.

Webster, J. J. \& Palmer, R. L. (2000). The childhood and family background of women with clinical eating disorders: a comparison with women with major depression and women without psychiatric disorder. Psychological Medicine 30, 53-60.

Yang, H. J., Soong, W. T., Kuo, P. H., Chang, H. L. \& Chen, W. J. (2004). Using the CES-D in a two-phase survey for depressive disorders among non-referred adolescents in Taipei: a stratumspecific likelihood ratio analysis. Journal of Affective Disorders $\mathbf{8 2}$, 419-430. 